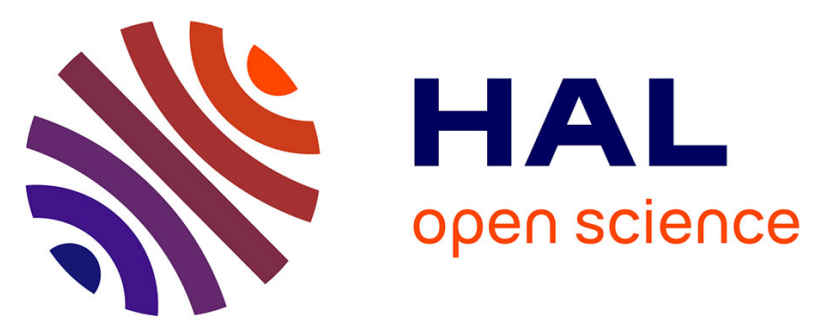

\title{
Electrical-field-induced structural change and charge transfer of lanthanide-salophen complexes assembled on carbon nanotube field effect transistor devices.
}

Gurvan Magadur, Fatima Zara Bouanis, Evgeny Norman, Regis Guillot, Jean-sébastien Lauret, Vincent Huc, Costel Sorin Cojocaru, Talal Mallah

\section{To cite this version:}

Gurvan Magadur, Fatima Zara Bouanis, Evgeny Norman, Regis Guillot, Jean-sébastien Lauret, et al.. Electrical-field-induced structural change and charge transfer of lanthanide-salophen complexes assembled on carbon nanotube field effect transistor devices.. Chemical Communications, 2012, 48, pp.9071-9073. 10.1039/c2cc34134d . hal-00793861

\section{HAL Id: hal-00793861 \\ https://hal.science/hal-00793861}

Submitted on 10 Jun 2013

HAL is a multi-disciplinary open access archive for the deposit and dissemination of scientific research documents, whether they are published or not. The documents may come from teaching and research institutions in France or abroad, or from public or private research centers.
L'archive ouverte pluridisciplinaire HAL, est destinée au dépôt et à la diffusion de documents scientifiques de niveau recherche, publiés ou non, émanant des établissements d'enseignement et de recherche français ou étrangers, des laboratoires publics ou privés. 


\title{
Electrical-field-induced structural change and charge transfer of lanthanide-salophen complexes assembled on carbon nanotube field effect transistor devices
}

\author{
Gurvan Magadur, ${ }^{\mathrm{a}}$ Fatima Bouanis, ${ }^{\mathrm{ab}}$ Evgeny Norman, ${ }^{\mathrm{b}}$ Regis Guillot, ${ }^{\mathrm{a}}$ \\ Jean-Seastien Lauret, ${ }^{\mathrm{c}}$ Vincent Huc, ${ }^{\mathrm{a}}$ Costel Sorin Cojocaru ${ }^{\mathrm{b}}$ and Talal Mallah ${ }^{\mathrm{a}}$ \\ ${ }^{a}$ Institut de Chimie Moléculaire et des Matériaux d’Orsay, \\ Université Paris Sud 11, CNRS, Bât. 420, 15 rue Georges Clemenceau, \\ 91405 Orsay Cedex, France. E-mail: talal.mallah@u-psud.fr, gurvan.magadur@u-psud.fr; Fax: 331 69154754; \\ Tel: 33169154749 \\ ${ }^{\mathrm{b}}$ Laboratoire de Physique des Interfaces et Couches Minces, Ecole Polytechnique, F-91128 Palaiseau, France \\ ${ }^{\mathrm{C}}$ Laboratoire de Photonique Quantique et Moléculaire, 61, avenue du Président Wilson, 94230 Cachan, France
}

DOI: $10.1039 / \mathrm{c2cc} 34134 \mathrm{~d}$

\section{ABSTRACT}

The application of a negative gate voltage on a carbon nanotube field effect transistor decorated by a binuclear Tb(III) complex leads to the generation of a negatively charged mononuclear one, presenting an electron density transfer to the nanotube and ambipolar behaviour.

Carbon nanotubes are very promising $1 \mathrm{D}$ materials in many general fields, such as mechanics, ${ }^{1}$ optics ${ }^{2,3}$ and electronics. ${ }^{4}$

Combining the unique transport properties of single-walled carbon nanotubes (SWNT) and those of organic or inorganic materials led to several breakthroughs in the last few years. In particular, SWNTs can act as sensors (gas, biomolecules, organic and inorganic compounds $)^{5,6}$ in different kinds of devices, such as Carbon Nanotube Field Effect Transistors (CNFET). ${ }^{4,7}$ In such devices, the gate-monitored transport property through the semiconducting nanotube is highly sensitive to its close environment. The functionalization of the nanotube by molecules induces a change in the transport allowing us to probe the assembled molecules. ${ }^{2,6,8}$ Recently, a supramolecular spin valve was designed and used as a magnetic probe thanks to the coupling of the magnetic properties of a rare earth complex with the electronic ones of CNFET. ${ }^{9}$

In this communication, we report on the solid-state structural transformation of the binuclear lanthanide-salophenbased complex $\left.\left[\mathrm{Tb}_{2} \text { (salophen) }\right)_{3}\right]$ (1) (where $\mathrm{H}_{2}$ salophen is disalicylidene-1,2-phenylenediamine) induced by the electrical field of the CNFET device. Rare earth complexes built using Schiff-base scaffold possess interesting optical and magnetic properties. Salophen was chosen as a base unit for the design

of the lanthanide complex because it possesses a delocalized $\mathrm{p}$ system, which can lead to non-covalent p-stacking inter- actions with the SWNT.

The $\left.\left[\mathrm{Tb}_{2} \text { (salophen) }\right)_{3}\right]$ binuclear complex is obtained via the reaction of $\mathrm{Tb}\left(\mathrm{NO}_{3}\right)_{3}$ and $\mathrm{H}_{2}$ salophen in the presence of triethylamine with a slight modification of the reported pro- cedure (see ESIw). ${ }^{10,11}$ Crystals suitable for structural studies were grown and the structure was solved.z The molecular arrangement consists of a binuclear triple-decker-like complex. The two $\mathrm{Tb}$ (III) ions have different surroundings: one has 8 bonds, 4 with a peripheral salophen and four with the bridging one, while the other $\mathrm{Tb}$ atom has only 7 bonds, four with the other peripheral salophen and only two with the bridging one. The seventh atom in the coordination sphere belongs to an ethanol molecule (Fig. $\mathbf{I}$ and S1, see ESIw). Prior to the transport studies, $\mathbf{1}$ and $\mathbf{1} / \mathrm{HiPCO}-\mathrm{SWNT}$ was charac- terized by electronic and photoluminescence studies that showed the absence of an interaction between the complex and the nanotubes (Fig. $\mathrm{S}_{2}$ and $\mathrm{S}_{3}$ see ESIw).

The transistors used in this study were obtained as we already reported (Fig. $\mathrm{S}_{4}$ and $\mathrm{S}_{5}$ see ESIw). ${ }^{12}$ Current $\left(\mathrm{I}_{\mathrm{ds}}\right)$ versus gate voltage $\left(V_{\mathrm{g}}\right)$ characteristics shows the expected p-type FET behaviour (ON state at $\mathrm{V}_{\mathrm{g}} \mathbf{O}$ o) with a very good $\mathrm{I}_{\mathrm{ON}} / \mathrm{I}_{\mathrm{OFF}}$ ratio between five and seven decades (Fig. $\mathrm{S}_{5}$, ESIw). The usual large hysteresis is the result of charge injection from the carbon nanotube to the nearby region. The measures are realized with a $2 \mathrm{~V}$ bias and $\mathrm{V}_{\mathrm{g}}$ is swept from $-20 \mathrm{~V}$ to $+20 \mathrm{~V}$.

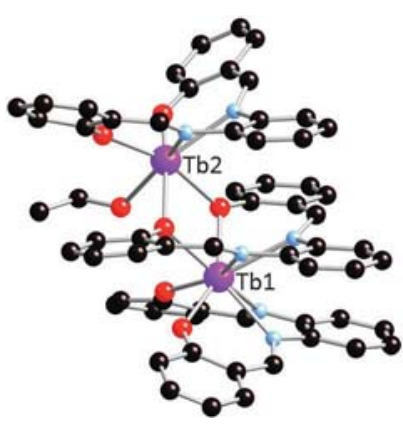

Fig. 1 A view of the structure of binuclear complex 1 showing the two different coordination spheres of the $\mathrm{Tb}(\mathrm{III})$ ions. 


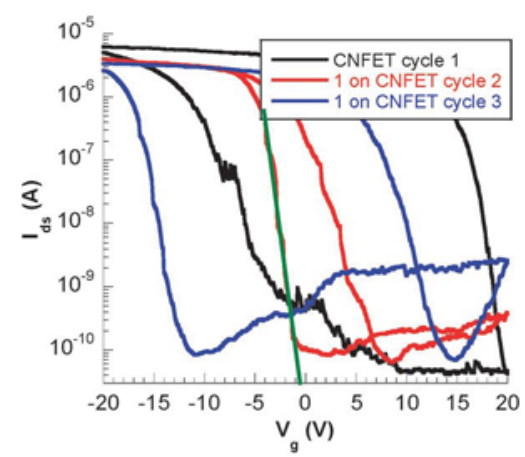

Fig. $2 I_{d s}$ vs. $V_{g}$ characteristics for a CNFET device before (black curve) and after the presence of $\mathbf{1}$ (red). The blue curve corresponds to a second cycle of the gate voltage. The curves are recorded within a bias of $2 \mathrm{~V}$.

The hybrids were produced by the evaporation of a $5 \mathrm{~mL}$ drop of a solution of $\mathbf{1}$ in dichloroethane (DCE) deposited on the CNTFET surface. Since our systems consist of transistors built on diluted mats of SWNT with gaps between the two electrodes of up to $5 \mathrm{~mm}$, the impact of any molecule assembled non-covalently on the CNFET conduction is mainly attributable to an interaction with the channel or its direct environment (dielectric surface, but not the channel-electrodes interface)., ${ }^{412}$ Three voltage cycles leading to $I_{d s}$ vs. $V_{g}$ plots were performed (Fig. 2): (i) for the bare transistor (first cycle, black), (ii) directly after the evaporation of the solution of $\mathbf{1}$ (second cycle, red) and (iii) a few minutes after the second cycle (third cycle, blue).y The first cycle corresponds to a p-type semiconductor nanotube with no ambipolar behavior, as is expected for a device in ambient air atmosphere. For the second cycle, as gate voltage is swept to positive values, the ON/OFF threshold voltage $\mathrm{V}_{\text {th }}$ shifts from 1.1 to $-0.9 \mathrm{~V}$ (Fig. 2) and the subthreshold swing $S_{w}=\left[\mathrm{dV}_{\mathrm{g}} / \mathrm{d} \log (\mathrm{I})\right]$ (green slope on Fig. 2.) increases in comparison to that of the bare device. Both of these effects contribute to reduce the width of the hysteretic character. This is attributed to a modification of the charge trapping process occurring at the SWNT-dielectric interface that is responsible for the hysteretic behaviour. ${ }^{4}$ It suggests that $\mathbf{1}$ does not interact electronically with the nanotube, but forms a layer of randomly organized molecules that partially isolate the conduction channel from its environment: it acts as a screen for the charge trapping phenomenon, thus decreasing the width of the hysteresis curve. This is consistent with the UV-visible and photoluminescence studies that $\mathbf{1}$ does not interact electronically with the nanotube (Fig. S3, see ESIw).

Finally, for the third cycle (blue curve) the aspect of the characteristic changes significantly again, showing many features that indicate the occurrence of an electronic interaction between a new molecular species and the nanotube. The width of the hysteresis loop has been restored to become similar to that of the bare device (as well as $\mathrm{S}_{\mathrm{w}}$ ), which is in line with the disappearance of the screening centres. The $V_{\text {th }}$ strongly decreases (DV $=-12.6 \mathrm{~V}$ ) in comparison to that of the bare transistor, as it is usually observed for non-covalently assembled molecules responsible of an electron density transfer phenomenon from the molecule to the SWNT. ${ }^{12}$ In addition to those changes, a small ambipolar character appears for the positive values of $\mathrm{V}_{\mathrm{g}}$. In summary, the application of a negative gate voltage (Fig. S6, see ESIw), z that produces an important holes current flow, modifies the layer of deposited molecules by deeply changing the nature of their interaction with the device. The charge transfer phenomenon suggests that the nature of the complex itself is modified, leading to a new entity able to assemble non-covalently on the surface of SWNT. It is important to note that the gate voltage was cycled several times after the third cycle and no noticeable change in the characteristics of the transistor was furthermore observed showing the stability of the new species.

The nature of the new species can be inferred by examining the structure of $\mathbf{1}$ and its behaviour in solution. 1 can be described as formed by the species $\left.[\mathrm{Tb} \text { (salophen })_{2}\right]^{-}$and $[\mathrm{Tb} \text { (salophen) }]^{+}$ linked together by two Tb-O bonds (Fig. 1). Costes et al. have already shown the presence of an equilibrium in solution between these two charged species and 1. ${ }^{10,11}$ Indeed, the chelating effect within the two new species is large enough to ensure their stability. We assume that the applied bias creates an electrical field in the close vicinity of the nanotube that produces enough energy to break $\mathbf{1}$ at its weakest bonds, i.e. the coordination $\mathrm{Tb}-\mathrm{O}$ bonds with the central salophen ligand, leading to the new charged species. Indeed, the nonsymmetrical binuclear complex must have an electrical dipole sensitive to the field generated by the applied bias. Furthermore, the driving force of such a phenomenon can be attributed to the electrostatic interaction between the holes (positive charges) flowing through the nanotube upon the application of a negative gate voltage and the negative charge of the $\left.[\mathrm{Tb} \text { (salophen })_{2}\right]^{-}$entity. In order to confirm our hypothesis that the formed species is indeed the $\left.[\mathrm{Tb} \text { (salophen })_{2}\right]^{-}$ complex, we synthesized it by mixing a stoichiometric amount of salophen and $\mathrm{Tb}\left(\mathrm{NO}_{3}\right)_{3}$ in dimethylsulfoxide (DMSO) in the presence of $\mathrm{CsCl}^{10,13}$ Even though single crystals suitable for structural studies were not obtained, the full characterisation of the powder confirmed the synthesis of the targeted complex that has the following formula Cs[Tb(salophen) $)_{2} \cdot 0.3 \mathrm{DMSO}$ (2) (Fig. 3 top, see ESIw).

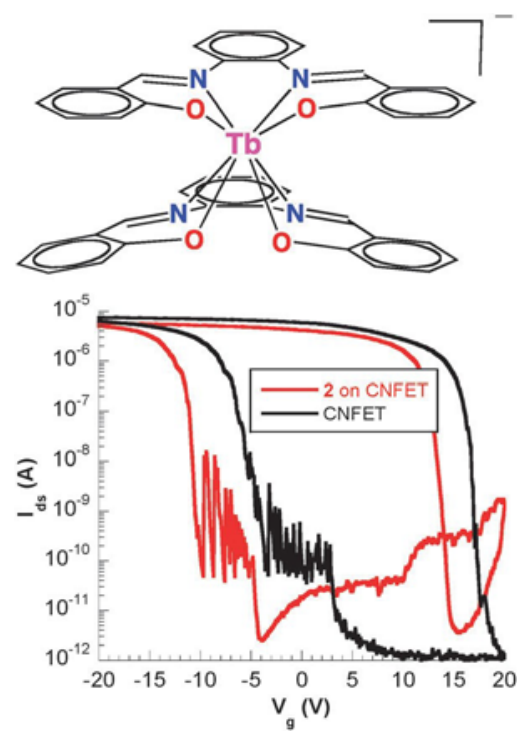

Fig. 3 A schematic view of the structure of 2 (top) and $I_{d s}$ vs. $V_{g}$ characteristics for a CNFET device before (black curve) and after (red curve) the assembly of 2 , the bias is $2 \mathrm{~V}$ (bottom). 


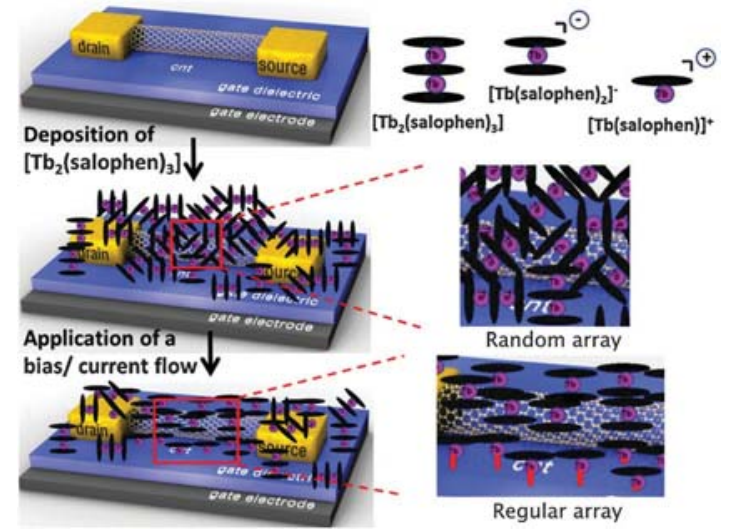

Fig. 4 A scheme of the global mechanism occurring during the deposition of the $\left.\left[\mathrm{Tb}_{2} \text { (salophen }\right)_{3}\right]$ complex and the application of a bias. The bonds between the $[\mathrm{Tb}(\text { salophen })]^{+}$complexes and the $\mathrm{SiO}_{2}$ surface are symbolized by red bold lines: $\mathrm{Tb}-\mathrm{O}$.

The crystal structure of a similar complex $\left(\mathrm{Ce}(\text { salophen })_{2}\right)$ has already been reported. ${ }^{14}$

In order to study the characteristics of 2 when assembled on the CNFET device, the same experiment as for 1 was carried out. Complex 2 behaves exactly as 1 after the third cycle in the first experiment. The width of the hysteresis loop is conserved, $\mathrm{V}_{\text {th }}$ shifts to a negative gate voltage value $(\mathrm{DV}=-6.6 \mathrm{~V})$ in comparison to the bare device and more importantly the same weak ambipolar character appears (Fig. 3). All of these characteristics are direct evidence that the molecular species obtained after the third cycle in the first experiment is indeed complex 2 (compare the blue curve of Fig. 2 to the red one of Fig. 3). We have checked that the addition of the pure $\mathrm{H}_{2}$ salophen, salophen ${ }^{2-}$ or $\mathrm{Tb}\left(\mathrm{NO}_{3}\right)_{3}$ on a CNFET device does not lead to the behaviour of complex 2, which is an indirect confirmation of our hypothesis.

We have demonstrated that the application of a bias together with a negative gate voltage induces enough energy in the vicinity of the nanotube belonging to a field-effect transistor to lead to a structural modification of the rare-earth binuclear complex. This modification is driven by the stabilizing electrostatic interaction between the positively charged nanotube of the FET for negative $V_{\mathrm{g}}$ and the negative complex 2 (Fig. 4, see ESIw). We prepared the whole series of binuclear complexes with Dy(III), Gd(III) and Ho(III). They all present exactly the same transport characteristics as 1 (Fig. S7, ESIw), which is direct evidence of the mechanism we propose, where the structure and the molecular architecture of the molecules play the main roles in the observed behaviour. Theoretical studies are needed to get a better insight into the origin of the electron transfer between 2 and the nanotube and particularly on the role of complex 1 that acts as a charge scatter modifying the charge trapping process occurring at the SWNT-dielectric interface.
We thank the CNRS, the Universite' Paris Sud 11 and the Ecole Polytechnique for financial support. The research described here has been also supported by Triangle de la Physique project "SECOND", convention No 2010-42T and the ANR project MolNanoSpin: o8-NANO-P110-48.

\section{Notes and references}

z CCDC 883777 contains the supplementary crystallographic data for this paper. These data can be obtained free of charge from the Cambridge Crystallographic Data Centre via http://www.ccdc.cam. ac.uk/data.

y Prior to this experiment, it was checked that pure DCE does not change the characteristics of the device.

$z$ In order to confirm that the change in the nature of the molecular species occurs at negative gate voltage, we performed the same experiment on a different device by cycling $\mathrm{V}_{\mathrm{g}}$ only in the -20 to $-8 \mathrm{~V}$ interval within a bias of $2 \mathrm{~V}$. We indeed observed that after the first cycle, the $\mathrm{I}_{\mathrm{ON}}$ value drops and is stabilized at the third cycle (Fig. S6, ESIw).

1 R. H. Baughman, A. A. Zakhidov and W. A. de Heer, Science, 2002, 297, 787 .

2 K. Besteman, J. O. Lee, F. G. M. Wiertz, H. A. Heering and C. Dekker, Nano Lett., 2003, 3, 727.

3 M. Freitag, Y. Martin, J. A. Misewich, R. Martel and P. H. Avouris, Nano Lett., 2003, 3, 1067; P. Avouris, J. Chen, M. Freitag, V. Perebeinos and J. C. Tsang, Phys. Status Solidi B, 2006, 243, 3197; P. Avouris, M. Freitag and V. Perebeinos, Nat. Photonics, 2008, 2, 341.

4 P. Avouris, Z. H. Chen and V. Perebeinos, Nat. Nanotechnol., 2007, 2, 605 .

5 C. P. Collier, G. Mattersteig, E. W. Wong, Y. Luo, K. Beverly, J. Sampaio, F. M. Raymo, J. F. Stoddart and J. R. Heath, Science, 200o, 289, 1172; K. Bradley, M. Briman, A. Star and G. Gruner, Nano Lett., 2004, 4, 253; X. F. Guo, L. M. Huang, S. O'Brien, P. Kim and C. Nuckolls, J. Am. Chem. Soc., 2005, 127, 15045; J. Borghetti, V. Derycke, S. Lenfant, P. Chenevier, A. Filoramo, M. Goffman, D. Vuillaume and J. P. Bourgoin, Adv. Mater., 2006, 18, 2535; L. Hu, Y. L. Zhao, K. Ryu, C. Zhou, J. F. Stoddart and G. Gruner, Adv. Mater., 2008, 20, 939; Y. L. Zhao, L. B. Hu, J. F. Stoddart and G. Gruner, Adv. Mater., 2008, 20, 1910.

6 J. Kong, N. R. Franklin, C. W. Zhou, M. G. Chapline, S. Peng, K. J. Cho and H. J. Dai, Science, 2000, 287, 622.

7 R. Martel, T. Schmidt, H. R. Shea, T. Hertel and P. Avouris, Appl. Phys. Lett., 1998, 73, 2447; S. J. Tans, A. R. M. Verschueren and C. Dekker, Nature, 1998, 393, 49; P. Avouris, Proceedings IEEE, 2003, 91, 1772.

8 M. Bockrath, J. Hone, A. Zettl, P. L. McEuen, A. G. Rinzler and R. E. Smalley, Phys. Rev. B: Condens. Matter Mater. Phys., 20oo, 61, 10606; P. C. Collins, M. S. Arnold and P. Avouris, Science, 2001, 292, 706; J. Kong, M. G. Chapline and H. J. Dai, Adv. Mater., 2001, 13, 1384; B. L. Allen, P. D. Kichambare and A. Star, Adv. Mater., 2007, 19, 1439; P. Bondavalli, P. Legagneux and D. Pribat, Sens. Actuators, B, 2009, 140, 304.

9 M. Urdampilleta, S. Klyatskaya, J. P. Cleuziou, M. Ruben and W. Wernsdorfer, Nat. Mater., 2011, 10, 502.

10 J. P. Costes, A. Dupuis and J. P. Laurent, Inorg. Chim. Acta, 1998, 268, 125.

11 J. P. Costes, J. P. Laussac and F. Nicodeme, J. Chem. Soc., Dalton Trans., 2002, 2731.

12 G. Magadur, J.-S. Lauret, G. Charron, F. Bouanis, E. Norman, V. Huc, C.-S. Cojocaru, S. Gomez-Coca, E. Ruiz and T. Mallah, J. Am. Chem. Soc., 2012, 134, 7896.

13 H. Y. Chen and R. D. Archer, Inorg. Chem., 1994, 33, 5195.

14 A. Terzis, D. Mentzafos and H. A. Tajmir-Riahi, Inorg. Chim. Acta, 1984, 84, 187. 